Article

\title{
Chloroplast Genome of the Folk Medicine and Vegetable Plant Talinum paniculatum (Jacq.) Gaertn.: Gene Organization, Comparative and Phylogenetic Analysis
}

\author{
Xia Liu*(1), Yuan Li, Hongyuan Yang and Boyang Zhou \\ State Key Laboratory of Food Nutrition and Safety, Key Laboratory of Food Nutrition and Safety, Ministry of \\ Education of China, College of Food Engineering and Biotechnology, Tianjin University of Science \& Technology, \\ No. 29, 13th Street, TEDA, Tianjin 300457, China; 13820282933@163.com (Y.L.); \\ yanghongyuan1218@sina.com (H.Y.); zhouboyang456@163.com (B.Z.) \\ * Correspondence: liuxia831930@163.com; Tel.: +86-22-6091-2406
}

Received: 8 March 2018; Accepted: 6 April 2018; Published: 9 April 2018

check for updates

\begin{abstract}
The complete chloroplast (cp) genome of Talinum paniculatum (Caryophyllale), a source of pharmaceutical efficacy similar to ginseng, and a widely distributed and planted edible vegetable, were sequenced and analyzed. The cp genome size of T. paniculatum is $156,929 \mathrm{bp}$, with a pair of inverted repeats (IRs) of 25,751 bp separated by a large single copy (LSC) region of $86,898 \mathrm{bp}$ and a small single copy (SSC) region of $18,529 \mathrm{bp}$. The genome contains 83 protein-coding genes, 37 transfer RNA (tRNA) genes, eight ribosomal RNA (rRNA) genes and four pseudogenes. Fifty one (51) repeat units and ninety two (92) simple sequence repeats (SSRs) were found in the genome. The pseudogene rpl23 (Ribosomal protein L23) was insert AATT than other Caryophyllale species by sequence alignment, which located in IRs region. The gene of trnK-UUU (tRNA-Lys) and rpl16 (Ribosomal protein L16) have larger introns in T. paniculatum, and the existence of matK (maturase K) genes, which usually located in the introns of $\operatorname{trnK}-U U U$, rich sequence divergence in Caryophyllale. Complete cp genome comparison with other eight Caryophyllales species indicated that the differences between T. paniculatum and P. oleracea were very slight, and the most highly divergent regions occurred in intergenic spacers. Comparisons of IR boundaries among nine Caryophyllales species showed that T. paniculatum have larger IRs region and the contraction is relatively slight. The phylogenetic analysis among 35 Caryophyllales species and two outgroup species revealed that T. paniculatum and P. oleracea do not belong to the same family. All these results give good opportunities for future identification, barcoding of Talinum species, understanding the evolutionary mode of Caryophyllale cp genome and molecular breeding of T. paniculatum with high pharmaceutical efficacy.
\end{abstract}

Keywords: Talinum paniculatum; chloroplast genome; medicinal plant; phylogeny

\section{Introduction}

Chloroplasts are the metabolic centers of our world due to the crucial role of converting sunlight into energy and releasing oxygen. Chloroplast genome encodes many key proteins that are involved in photosynthesis and other important metabolic processes for plant interactions with their environment, such as drought, salt and light [1-4]. The availability of over 2400 sequenced chloroplast genomes (http:/ / www.ncbi.nlm.nih.gov/genomes /) gave us insights to understand the plant biology diversity, evolution, climatic adaptation, DNA barcoding and expression high-value agricultural or biomedical products by genetic engineering [1,2,5-9]. 
Java ginseng (Talinum paniculatum (Jacq.) Gaertn.), one of the most popular medicinal plants, belongs to the genus Talinum Adans. in the Portulacaceae family of the Caryophyllales. It is widely used for many ailments, including cancer, diabetes, hepatic disorders, leishmaniasis and reproductive disorders due to its high concentrations of alkaloids, flavonoids, tannins, steroids, and triterpenes [10-14]. The root of T. paniculatum has lots of valuable components, which are similar to those in Panax [15]. Meanwhile, the leaves of T. paniculatum are widely used as a green leafy vegetable for human consumption in many parts of South America, Africa and Asia.

Like Portulaca oleracea, T. paniculatum has high adaptability to drought, salinity, and low nutrient conditions [16]. Few reports have been published on the genetic diversity of chloroplast DNA from the Portulacaceae. The relationship of Portulaca to Anacampserotaceae, Cactaceae Juss, and Talinaceae is still uncertain [17-20]. The Portulacaeae are composed only a single genus of Portulace [21]. Molecular barcodes based on the chloroplast genome have shown great potential for species discrimination, especially between closely related taxa, but to date, chloroplast genome sequences of only two genus of the Portulacaceae have been analyzed, which are Carnegiea gigantean and Portulaca oleracea [22-24]. At both the species and population levels, the complete chloroplast genome sequence might enhance our ability to explore reliable barcoding for accurate plant identification $[6,7,25]$.

Here, we report for the first time the complete cp genome sequence of T. paniculatum. Meanwhile, the gene structure and organization of the cp genome were analyzed. Besides, the cp genome sequences was compared with other genus of Caryophyllales. We also present the results of phylogenetic analyses of DNA sequences for 48 protein-coding genes from T. paniculatum, 35 Caryophyllales cp genomes and two outgroups.

\section{Results}

\subsection{Features of the T. paniculatum cp Genome}

The chloroplast genome of T. paniculatum, a typical quadripartite structure, is $156,929 \mathrm{bp}$ in size, including a LSC region of 86,898 bp ranging from trnH-GUG to rps19 (Ribosomal protein S19), a SSC region of 18,529 bp from $n d h F$ (NAD(P)H dehydrogenase) to ycf1 (hypothetical protein 1 gene), a pair of IR regions of 25,751 bp from rps19 to pseudogene ycf1 and ranging from ycf1 to rps19, respectively (Figure 1 and Table 1). The GC content of $\mathrm{cp}$ genome in the cp total, LSC (large single copy), SSC (small single copy), IRA (inverted repeat A region) and IRB (inverted repeat B region) is $36.79 \%, 34.6 \%, 30.5 \%, 42.7 \%$ and $42.7 \%$, respectively (Table 1 ), which is similar to the cp genome of other Caryophyllales $[23,24]$ and the higher GC content in IR regions. A higher AT representation at the third codon position and second codon position was significant, which is one of the common characteristics of the chloroplast genome [26-29]. The overall cp genome of T. paniculatum is made up of $49.98 \%$ protein-coding regions, $5.76 \%$ rRNAs, $1.78 \%$ tRNAs and $50.02 \%$ non-coding regions.

Table 1. Chloroplast genome composition of Talinum paniculatum (Jacp) Gaertn.

\begin{tabular}{|c|c|c|c|c|c|c|c|c|c|}
\hline Region & Size (bp) & $\mathrm{T}(\mathrm{U})(\%)$ & $\mathrm{C}(\%)$ & A (\%) & G (\%) & Genes & Protein-Coding Genes & tRNA Genes & rRNA Genes \\
\hline LSC & 86,898 & 33.2 & 17.8 & 32.2 & 16.8 & 83 & 56 & 22 & 0 \\
\hline SSC & 18,529 & 34.6 & 15.9 & 34.9 & 14.6 & 12 & 12 & 1 & 0 \\
\hline IRA & 25,751 & 29.0 & 22.3 & 28.2 & 20.4 & 19 & 7 & 7 & 4 \\
\hline IRB & 25,751 & 28.2 & 20.4 & 29.0 & 22.3 & 19 & 8 & 7 & 4 \\
\hline Total & 156,929 & 31.8 & 19.0 & 30.7 & 18.5 & 128 & $83(4)$ & $37(7)$ & $8(4)$ \\
\hline CDS & 78,438 & 31.5 & 17.6 & 30.8 & 20.1 & & & & \\
\hline 1st position & 26,146 & 23.7 & 18.8 & 30.7 & 26.7 & & & & \\
\hline 2nd position & 26,146 & 32.7 & 20.2 & 29.4 & 17.8 & & & & \\
\hline 3rd position & 26,146 & 38.1 & 13.7 & 32.4 & 15.7 & & & & \\
\hline
\end{tabular}

CDS: protein-coding regions. The numbers in brackets represent the number of repeated genes. 


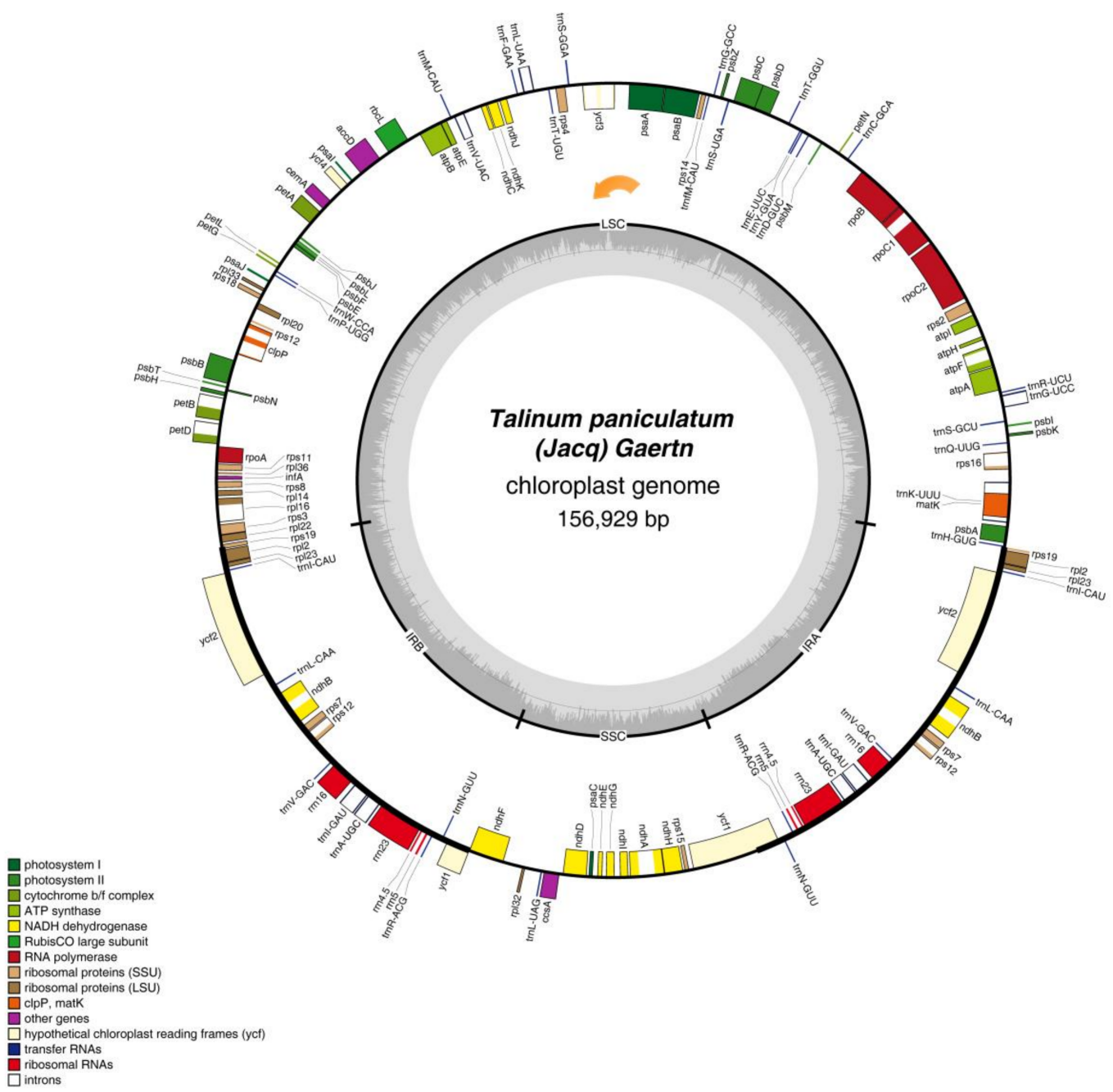

Figure 1. The complete chloroplast genome map of Talinum paniculatum (Jacp) Gaertn. Genes are color-coded based on functional group. Genes drawn inside the circle are transcribed clockwise, and those outside are transcribed counterclockwise. The genome orientation are the orange arrow.

In total, there are 113 unique functional genes and four pseudogenes in the chloroplast gene of $T$. paniculatum (Tables 1 and 2). Among 113 functional genes, 79 protein-coding genes, 30 distinct tRNAs and four distinct rRNAs were contained (Table 2). Remarkably, because all rRNA, seven tRNA, four protein-coding genes and one pseudogene are replicated in the IR regions, the total genes in Figure 1 and Table 2 are 132. Fifty six protein-coding and 22 tRNA genes are located in LSC region, but only 12 protein-coding genes and one tRNA are located in the SSC region. Meanwhile, all eight rRNA are sited in IR regions, which has been found to be common in most cp genomes [23,30]. The ycf1 gene is located at the IR and SSC boundary region, the rps19 gene was located at the IR and LSC boundary region. Pseudogenes of rpl23, rps19, ycf1 are all located in IR regions.

Among the 113 unique genes in T. paniculatum cp genome, 17 genes contain introns, including six tRNA genes and 11 protein-coding genes. Most of them only contain one intron, while like to other angiosperms, ycf3, clpP and rps12 have two introns (Table 3). Twelve genes with introns are located in the LSC, four genes with introns are located in IR regions, and only one gene with intron is located in the SSC region. Interestingly, the $3^{\prime}$ exon of $r p s 12$ is duplicated in IRs, but its $5^{\prime}$ exon shared by the $3^{\prime}$ exon was located in the LSC region. Consistent with many research results, the matK gene was inserted into the intron of $\operatorname{trnK}-U U U$, so the intron of trnK-UUU became so maximal $[23,30]$. Comparing these 
17 introns with $P$. oleracea, most of them is shorter in T. paniculatum, whereas the introns of petB, petD are larger, and rpoC1 intron is the same size [23].

Table 2. Genes of the Talinum paniculatum (Jacp) Gaertn.

\begin{tabular}{|c|c|c|}
\hline Group of Genes & Name of Gene & No. \\
\hline Photosytem I & $p s a A, p s a B, p s a C, p s a I, p s a J$ & 5 \\
\hline Photosytem II & $\begin{array}{l}p s b A, p s b B, p s b C, p s b D, p s b E, p s b F, p s b H, p s b I, p s b J, \\
p s b K, p s b L, p s b M, p s b N, p s b T, p s b Z\end{array}$ & 15 \\
\hline Cytochrome b/f complex & $\operatorname{pet} A, \operatorname{pet} B, \operatorname{pet} D, \operatorname{pet} G, \operatorname{pet} L, \operatorname{pet} N$ & 6 \\
\hline ATP system & $\operatorname{atp} A, \operatorname{atpB}, a t p F, a t p F, a t p H$, atpI & 6 \\
\hline NADH dehydrogenase & $\begin{array}{l}n d h A, n d h B *, n d h C, n d h D, n d h E, n d h F, n d h G, n d h H, \\
n d h I, n d h J, n d h K\end{array}$ & 12 \\
\hline RuBisCO large subnit & $r b c L$ & 1 \\
\hline RNA polymerase & rроA, гров, гроС1, гроС2 & 4 \\
\hline Ribosomal proteins (SSU) & $\begin{array}{l}\text { rps2, rps3, rps4, rps7 }{ }^{*}, r p s 8, r p s 11, r p s 12{ }^{*}, r p s 14, r p s 15, \\
\text { rps16, rps18, rps19 }\end{array}$ & 14 \\
\hline Ribosomal proteins (LSU) & rpl2, rpl14, rpl16, rpl19, rpl20, rpl22, rpl32, rpl33, rpl36 & 9 \\
\hline Miscellaneous proteins & $\operatorname{acc} D, \operatorname{cem} A, \operatorname{ccs} A, \operatorname{clp} P, \inf A, \operatorname{mat} K$ & 6 \\
\hline \multirow[t]{2}{*}{ Hypothetical chloroplast reading frames (ycf) } & $y c f 1, y c f 2 *, y c f 3, y c f 4$ & 5 \\
\hline & 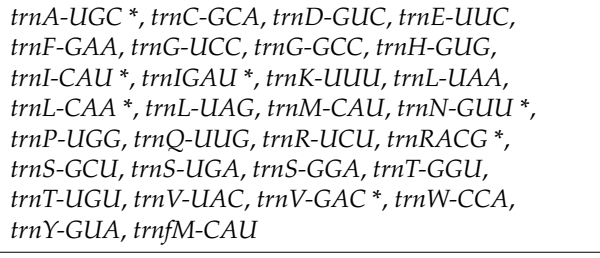 & 37 \\
\hline Ribosomal RNAs & $\operatorname{rrn} 4.5^{*}, \operatorname{rrn} 5^{*}, \operatorname{rrn} 16^{*}, \operatorname{rrn} 23^{*}$ & 8 \\
\hline Pseudogene & $r p l 23 *, r p s 19, y c f 1$ & 4 \\
\hline Total & & 132 \\
\hline
\end{tabular}

Table 3. The intron-containing genes in the T. paniculatum cp genome and the lengths of the exons and introns.

\begin{tabular}{|c|c|c|c|c|c|c|c|}
\hline No. & Gene & Location & ExonI (bp) & IntronI (bp) & ExonII (bp) & IntronII (bp) & ExonIII (bp) \\
\hline 1 & trnK-UUU & LSC & 35 & 2502 & 37 & & \\
\hline 2 & rps16 & LSC & 202 & 867 & 41 & & \\
\hline 3 & $\operatorname{trn} G-U C C$ & LSC & 23 & 707 & 48 & & \\
\hline 4 & atpF & LSC & 410 & 745 & 145 & & \\
\hline 5 & rpoc1 & LSC & 1611 & 794 & 432 & & \\
\hline 6 & $y c f 3$ & LSC & 153 & 773 & 229 & 769 & 125 \\
\hline 7 & trnL-UAA & LSC & 37 & 599 & 50 & & \\
\hline 8 & $\operatorname{trn} V-U A C$ & LSC & 35 & 586 & 38 & & \\
\hline 9 & $c l p P$ & LSC & 229 & 590 & 291 & 894 & 71 \\
\hline 10 & petB & LSC & 6 & 768 & 642 & & \\
\hline 11 & petD & LSC & 8 & 792 & 475 & & \\
\hline 12 & rpl16 & LSC & 399 & 1102 & 9 & & \\
\hline 13 & $n d h B *$ & IR & 756 & 668 & 777 & & \\
\hline 14 & $\operatorname{rps} 12 *$ & IR & 114 & - & 232 & 533 & 26 \\
\hline 15 & $\operatorname{trnI-GAU}$ * & IR & 37 & 947 & 35 & & \\
\hline 16 & $\operatorname{trn} A-U G C^{*}$ & IR & 38 & 818 & 35 & & \\
\hline 17 & $n d h A$ & SSC & 539 & 1087 & 553 & & \\
\hline
\end{tabular}

* indicates duplicated gene.

\subsection{Codon Usage of the T. paniculatum cp Genome}

As shown in Table 4, total 26,146 codons involved in the protein-coding in T. paniculatum. Among 26,146 codons, the amino acids used most frequently were leucine and isoleucine, which encode in $2780(10.63 \%)$ and $2258(8.63 \%)$ codons, respectively. While only $303(1.50 \%)$ codons encode cysteine as the least frequent universal amino acid (Table 4). 
Table 4. Codon usage in the T. paniculatum cp genome.

\begin{tabular}{|c|c|c|c|c|c|c|c|c|c|c|c|c|c|c|c|}
\hline Amino Acid & Codon & Count & RSCU & Amino Acid & Codon & Count & RSCU & Amino Acid & Codon & Count & RSCU & Amino Acid & Codon & Count & RSCU \\
\hline Phe & UUU(F) & 975 & 1.3 & Ser & $\mathrm{UCU}(\mathrm{S})$ & 556 & 1.67 & Tyr & UAU(Y) & 779 & 1.61 & Stop & $\left.\mathrm{UGA}^{*}\right)$ & 20 & 0.72 \\
\hline Phe & UUC(F) & 527 & 0.7 & Ser & UCC(S) & 331 & 0.99 & Tyr & UAC(Y) & 190 & 0.39 & $\operatorname{Trp}$ & UGG(W) & 460 & 1 \\
\hline Leu & UUA(L) & 854 & 1.84 & Ser & UCA(S) & 408 & 1.22 & Stop & $\left.\mathrm{UAA}^{*}\right)$ & 46 & 1.66 & Ala & GCU(A) & 615 & 1.75 \\
\hline Leu & UUG(L) & 554 & 1.2 & Ser & UCG(S) & 187 & 0.56 & Stop & UAG $\left({ }^{*}\right)$ & 17 & 0.61 & Ala & GCC(A) & 234 & 0.66 \\
\hline Leu & CUC(L) & 179 & 0.39 & Ser & AGC(S) & 127 & 0.38 & His & $\mathrm{CAC}(\mathrm{H})$ & 155 & 0.51 & Ala & GCG(A) & 144 & 0.41 \\
\hline Leu & CUA(L) & 408 & 0.88 & Pro & $\mathrm{CCU}(\mathrm{P})$ & 426 & 1.6 & Gln & CAA(Q) & 729 & 1.54 & Arg & CGU(R) & 360 & 1.36 \\
\hline Leu & CUG(L) & 184 & 0.4 & Pro & $\mathrm{CCC}(\mathrm{P})$ & 200 & 0.75 & Gln & CAG(Q) & 216 & 0.46 & Arg & CGC(R) & 92 & 0.35 \\
\hline Ile & AUU(I) & 1130 & 1.5 & Pro & $\mathrm{CCA}(\mathrm{P})$ & 299 & 1.12 & Asn & $\mathrm{AAU}(\mathrm{N})$ & 960 & 1.53 & Arg & CGA(R) & 366 & 1.38 \\
\hline Ile & AUC(I) & 410 & 0.54 & Pro & CCG(P) & 143 & 0.54 & Asn & AAC(N) & 297 & 0.47 & Arg & CGG(R) & 120 & 0.45 \\
\hline Met & AUG(M) & 607 & 1 & Thr & $\mathrm{ACC}(\mathrm{T})$ & 250 & 0.76 & Lys & AAG(K) & 357 & 0.5 & Arg & AGG(R) & 175 & 0.66 \\
\hline Val & GUU(V) & 514 & 1.48 & Thr & $\mathrm{ACA}(\mathrm{T})$ & 402 & 1.22 & Asp & GAU(D) & 883 & 1.66 & Gly & GGU(G) & 552 & 1.26 \\
\hline Val & GUC(V) & 160 & 0.46 & Thr & ACG(T) & 134 & 0.41 & Asp & GAC(D) & 184 & 0.34 & Gly & GGC(G) & 190 & 0.43 \\
\hline Val & GUA(V) & 522 & 1.5 & Cys & UGU(C) & 235 & 1.55 & Glu & GAA(E) & 1041 & 1.53 & Gly & GGA(G) & 712 & 1.62 \\
\hline Val & GUG(V) & 194 & 0.56 & Cys & UGC(C) & 68 & 0.45 & Glu & GAG(E) & 323 & 0.47 & Gly & GGG(G) & 302 & 0.69 \\
\hline
\end{tabular}

RSCU: Relative synonymous codon usage. RSCU > 1 are highlighted in bold. * indicates stop codon. 
The relative synonymous codon usage (RSCU) has been divided into four models, including lack of bias (RSCU < 1.0), low bias (1.0 < RSCU< 1.2), moderately biased $(1.2<\mathrm{RSCU}<1.3)$ and highly biased (RSCU > 1.3) [30,31]. As shown in Table 4, there are 32 lack of bias codons with values $<1.0$, except tryptophan and methionine, four low bias codons, four moderately biased codons and 21 highly biased codons, respectively. The TAA stop codon was found to be preferred. Meanwhile, due to 29 preferred synonymous codons (RSCU > 1.0) end with A or T, the third position of CDS contains $70.5 \% \mathrm{~A}$ or $\mathrm{T}$ bases, a significantly higher percentage than in the 2 nd position (62.1\%) or the 1 st position (54.4\%) (Tables 1 and 4). The results showed that the bias was significant in usage of synonymous codons except tryptophan and methionine in T. paniculatum as well as A/T ending rich in cp genome. These results revealed that the RSCU and codon usage exsited biased codon usage, which was consistent with previous reports in cp genomes of higher plants [32,33].

\subsection{Repeats Structure and SSR in T. paniculatum cp Genome}

Analysis of the repeat structure analysis using REPuter detected a total of 51 repeat sequences, including 20 forward repeats, 21 palindromic repeats, one complement repeats and nine reverse repeats in the cp genome of T. paniculatum (Table 5). The repeats range from 30 to $61 \mathrm{bp}$ in length and are mostly located in the intergenic spacer (IGS) and intron sequences. Twenty five repeats are located in exons of matK, trnS-GGA, trnG-UCC, $p s a B, p s a A$ and ycf2 genes, respectively. A comparative analysis revealed that 30-39 bp were the most repetitive in cp genome of seven species in Caryophyllales (Figure 2). Complement repeats were rare, as only T. paniculatum and C. gigantea contain them [24]. The reverse repeats of T. paniculatum are the most in the seven cp genomes.

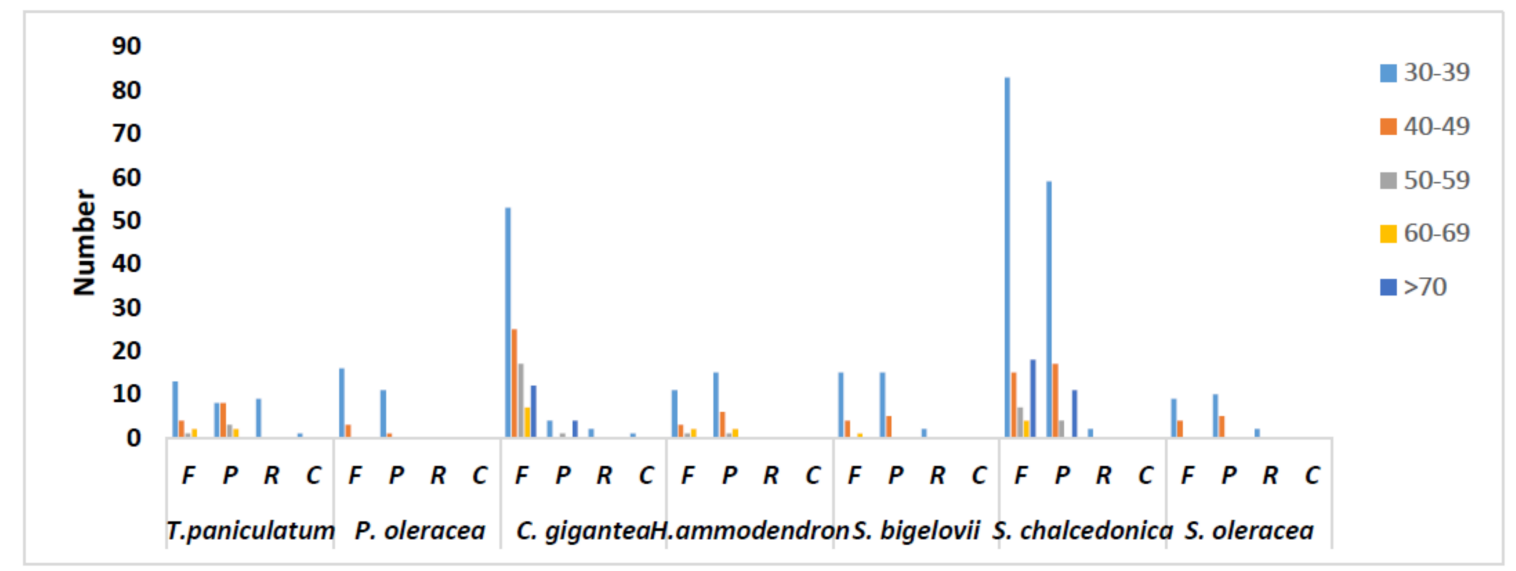

Figure 2. Repeat sequences in seven chloroplast genomes of Caryophyllales. REPuter was used to identify repeat sequences with length $\geq 30 \mathrm{bp}$ and sequence identify $\geq 90 \%$ in the chloroplast genomes. F, P, R and C indicate the repeat types forward, palindrome, reverse and complement, respectively.

There are 92 simple sequence repeats (SSRs) in the T. paniculatum chloroplast genome, the majority of which were mononuclear repeats (68). Twelve dinucleotide repeats, five trinucleotide repeats and seven pentanucleotide repeats were also found in T. paniculatum cp genome (Table 6, Figure 3). Whereas, only seven SSRs located in the CDSs (Table 7), including four mononucleotide, one dinucleotide and two pentanucleotide SSRs. The results indicate that all of the SSRs in CDs are located in the LSC region and most of them are AT repeats, which is consistent with the view that SSRs in cp genomes contribute to AT richness [32]. 
Table 5. Repeat sequences distribution in the T. paniculatum (Jacp) Gaertn chloroplast genome.

\begin{tabular}{|c|c|c|c|c|c|c|c|}
\hline No. & Size (bp) & Type & Repeat 1 Start & Repeat 1 Location & Repeat 2 Start & Repeat 2 Location & Location \\
\hline 1 & 35 & $\mathrm{~F}$ & 3144 & matK & 6441 & IGS (rps16, trnQ-UUG) & LSC \\
\hline 2 & 30 & $\mathrm{P}$ & 4153 & IGS (trnK-UUU (exon), rps16) & 4211 & IGS (trnK-UUU (exon), rps16) & LSC \\
\hline 3 & 30 & $\mathrm{R}$ & 4578 & IGS (trnK-UUU (exon), rps16) & 4581 & IGS (trnK-UUU (exon), rps16) & LSC \\
\hline 4 & 30 & $\mathrm{C}$ & 4581 & IGS (trnK-UUU (exon), rps16) & 4582 & IGS (trnK-UUU (exon), rps16) & LSC \\
\hline 5 & 30 & $\mathrm{R}$ & 6862 & IGS (trnQ-UUG, $p s b K)$ & 8268 & IGS (trnS-GCU, trnG-UCC) & LSC \\
\hline 6 & 30 & $\mathrm{~F}$ & 7743 & IGS (psbI, trnS-GCU) & 7770 & IGS (psbI, trnS-GCU) & LSC \\
\hline 7 & 32 & $\mathrm{~F}$ & 7896 & IGS (psbI, trnS-GCU) & 36,017 & IGS ( $p s b C, t r n S-U G A)$ & LSC \\
\hline 8 & 30 & $\mathrm{P}$ & 7898 & IGS ( $p s b I, t r n S-G C U)$ & 46,268 & trnS-GGA & LSC \\
\hline 9 & 37 & $\mathrm{R}$ & 8258 & IGS (trnS-GCU, trnG-UCC) & 8261 & IGS (trnS-GCU, trnG-UCC) & LSC \\
\hline 10 & 37 & $\mathrm{R}$ & 8258 & IGS (trnS-GCU, trnG-UCC) & 8264 & IGS (trnS-GCU, trnG-UCC) & LSC \\
\hline 11 & 35 & $\mathrm{~F}$ & 8258 & IGS (trnS-GCU, trnG-UCC) & 8277 & IGS (trnS-GCU, trnG-UCC) & LSC \\
\hline 12 & 35 & $\mathrm{R}$ & 8266 & IGS (trnS-GCU, trnG-UCC) & 8277 & IGS (trnS-GCU, trnG-UCC) & LSC \\
\hline 13 & 34 & $\mathrm{R}$ & 8258 & IGS (trnS-GCU, trnG-UCC) & 8261 & IGS (trnS-GCU, trnG-UCC) & LSC \\
\hline 14 & 33 & F & 8261 & IGS (trnS-GCU, trnG-UCC) & 8283 & IGS (trnS-GCU, trnG-UCC) & LSC \\
\hline 15 & 32 & $\mathrm{R}$ & 8263 & IGS (trnS-GCU, trnG-UCC) & 8280 & IGS (trnS-GCU, trnG-UCC) & LSC \\
\hline 16 & 31 & $\mathrm{~F}$ & 8261 & IGS (trnS-GCU, trnG-UCC) & 8264 & IGS (trnS-GCU, trnG-UCC) & LSC \\
\hline 17 & 31 & $\mathrm{R}$ & 8261 & IGS (trnS-GCU, trnG-UCC) & 8280 & IGS (trnS-GCU, trnG-UCC) & LSC \\
\hline 18 & 31 & $\mathrm{R}$ & 8267 & IGS (trnS-GCU, trnG-UCC) & 29,873 & IGS (psbM, trnD-GUC) & LSC \\
\hline 19 & 30 & $\mathrm{P}$ & 8267 & IGS (trnS-GCU, trnG-UCC) & 62,668 & IGS $(y c f 4, \operatorname{cem} A)$ & LSC \\
\hline 20 & 30 & $\mathrm{P}$ & 8280 & IGS (trnS-GCU, trnG-UCC) & 31,428 & IGS (trnE-UUC, trnT-GGU) & LSC \\
\hline 21 & 31 & $\mathrm{~F}$ & 9566 & $\operatorname{trn} G-U C C$ & 37,057 & $\operatorname{trn} G-G C C$ & LSC \\
\hline 22 & 30 & $\mathrm{P}$ & 36,019 & IGS ( $p s b C, t r n S-U G A)$ & 46,268 & $\operatorname{trnS}-G G A$ & LSC \\
\hline 23 & 30 & F & 39,314 & $p s a B$ & 41,538 & $p s a A$ & LSC \\
\hline 24 & 42 & $\mathrm{~F}$ & 44,540 & ycf3 (intronII) & 123,558 & $n d h A$ (intron) & LSC, SSC \\
\hline 25 & 39 & $\mathrm{~F}$ & 44,543 & ycf3 (intronII) & 100,738 & IGS $(r p s 12, \operatorname{trn} V-G A C)$ & LSC, IRb \\
\hline 26 & 39 & $\mathrm{P}$ & 44,543 & ycf3 (intronII) & 143,050 & IGS (trnV-GAC, rps12) & LSC, IRa \\
\hline 27 & 30 & $\mathrm{~F}$ & 44,555 & ycf3 (intronII) & 100,750 & IGS $(r p s 12, t r n V-G A C)$ & LSC, IRb \\
\hline 28 & 30 & $\mathrm{P}$ & 44,555 & ycf3 (intronII) & 143,047 & IGS (trnV-GAC, rps12) & LSC, IRa \\
\hline 29 & 40 & $\mathrm{P}$ & 76,849 & IGS $(p s b T, p s b N)$ & 76,849 & IGS $(p s b T, p s b N)$ & LSC \\
\hline 30 & 30 & $\mathrm{P}$ & 84,344 & IGS (trnS-GCU, trnG-UCC) & 84,346 & IGS (trnS-GCU, trnG-UCC) & LSC \\
\hline 31 & 61 & $\mathrm{~F}$ & 93,517 & $y c f 2$ & 93,535 & $y c f 2$ & $\mathrm{IRb}$ \\
\hline 32 & 61 & $\mathrm{P}$ & 93,517 & ycf2 & 150,231 & $y c f 2$ & IRb, IRa \\
\hline 33 & 61 & $\mathrm{P}$ & 93,535 & ycf 2 & 150,249 & ycf 2 & IRb, IRa \\
\hline 34 & 61 & $\mathrm{~F}$ & 150,231 & $y c f 2$ & 150,249 & $y c f 2$ & IRa \\
\hline 35 & 52 & $\mathrm{~F}$ & 93,526 & ycf 2 & 93,544 & ycf 2 & $\mathrm{IRb}$ \\
\hline 36 & 52 & $\mathrm{P}$ & 93,526 & ycf2 & 150,231 & ycf2 & IRb, IRa \\
\hline 37 & 52 & $\mathrm{P}$ & 93,544 & ycf2 & 150,249 & ycf2 & IRb, IRa \\
\hline 38 & 34 & $\mathrm{~F}$ & 93,526 & $y c f 2$ & 93,562 & $y c f 2$ & IRb \\
\hline 39 & 34 & $\mathrm{P}$ & 93,526 & $y c f 2$ & 150,231 & $y c f 2$ & IRb, IRa \\
\hline 40 & 34 & $\mathrm{P}$ & 93,562 & ycf2 & 150,267 & ycf2 & $\mathrm{IRb}, \mathrm{IRa}$ \\
\hline 41 & 43 & $\mathrm{~F}$ & 93,517 & ycf 2 & 93,533 & ycf2 & $\mathrm{IRb}$ \\
\hline 42 & 43 & $\mathrm{P}$ & 93,517 & $y c f 2$ & 150,231 & $y c f 2$ & IRb, IRa \\
\hline
\end{tabular}


Table 5. Cont.

\begin{tabular}{|c|c|c|c|c|c|c|c|}
\hline No. & Size (bp) & Type & Repeat 1 Start & Repeat 1 Location & Repeat 2 Start & Repeat 2 Location & Location \\
\hline 43 & 43 & $\mathrm{P}$ & 93,553 & $y c f 2$ & 150,267 & $y c f 2$ & IRb, IRa \\
\hline 44 & 43 & $\mathrm{~F}$ & 150,231 & $y c f 2$ & 150,267 & $y c f 2$ & IRa \\
\hline 45 & 40 & $\mathrm{~F}$ & 100,738 & IGS (rpsi2, trnV-GAC) & 123,561 & $n d h A$ (intron) & $\mathrm{IRb}, \mathrm{SSC}$ \\
\hline 46 & 34 & $\mathrm{~F}$ & 109,506 & IGS (rrn4.5, rrn5) & 109,538 & IGS (rrn4.5, rrn5) & $\mathrm{IRb}$ \\
\hline 47 & 34 & $\mathrm{~F}$ & 109,506 & IGS (rrn4.5, rrn5) & 134,255 & IGS (rrn5, rrn4.5) & $\mathrm{IRb}, \mathrm{IRa}$ \\
\hline 48 & 34 & $\mathrm{P}$ & 109,538 & IGS (rrn4.5, rrn5) & 134,287 & IGS (rrn5, rrn4.5) & $\mathrm{IRb}, \mathrm{IRa}$ \\
\hline 49 & 34 & $\mathrm{P}$ & 134,255 & IGS (rrn5, rrn4.5) & 134,287 & IGS (rrn5, rrn4.5) & IRa \\
\hline 50 & 38 & $\mathrm{P}$ & 118,646 & $\operatorname{IGS}(\operatorname{ccs} A, n d h D)$ & 118,646 & $\operatorname{IGS}(\operatorname{ccs} A, n d h D)$ & SSC \\
\hline 51 & 40 & $\mathrm{P}$ & 123,561 & $n d h A$ (intron) & 143,049 & IGS(trnV-GAC, rps12) & SSC, IRa \\
\hline
\end{tabular}

F: forward repeat; P: palindrome (inverted) repeat; R: reverse repeat; C: complement repeat. IGS: intergenic spacer 
Table 6. Frequency of simple sequence repeats in the T. paniculatum chloroplast genome.

\begin{tabular}{|c|c|c|c|c|c|c|c|c|c|c|c|c|c|}
\hline Length Unit & 10 & 10 & 11 & 12 & 13 & 14 & 15 & 16 & 17 & 18 & 19 & 20 & Total \\
\hline $\mathrm{A}$ & 15 & 15 & 3 & 8 & 1 & 1 & 3 & & & 1 & 1 & & 33 \\
\hline $\mathrm{T}$ & 14 & 14 & 4 & 7 & 3 & 2 & 1 & & 1 & & 1 & & 33 \\
\hline $\mathrm{C}$ & 1 & 1 & & & & & & & & & & & 1 \\
\hline G & 1 & 1 & & & & & & & & & & & 1 \\
\hline AG & 1 & 1 & & & & & & & & & & & 1 \\
\hline AT & 4 & 4 & & 3 & & & & & & & & & 7 \\
\hline $\mathrm{TA}$ & 2 & 2 & & 1 & & & & 1 & & & & & 4 \\
\hline AAT & 1 & 1 & & & & & & & & & & & 1 \\
\hline ATA & & & & 1 & & & & & & & & & 1 \\
\hline TTA & & & & 2 & & & & & & & & & 2 \\
\hline TAT & & & & 1 & & & & & & & & & 1 \\
\hline AGGT & & & & 1 & & & & & & & & & 1 \\
\hline ATGG & & & & 1 & & & & & & & & & 1 \\
\hline AATT & & & & 1 & & & & & & & & & 1 \\
\hline CTAC & & & & 1 & & & & & & & & & 1 \\
\hline TTTC & & & & 1 & & & & & & & & & 1 \\
\hline TAAT & & & & 1 & & & & & & & & & 1 \\
\hline GGAA & & & & 1 & & & & & & & & & 1 \\
\hline
\end{tabular}

Table 7. Simple sequence repeats in the CDSs of the T. paniculatum chloroplast genome.

\begin{tabular}{cccccccc}
\hline No. & Type & Motif & Size & Start & End & Location & Region \\
\hline 1 & P1 & (A)10 & 10 & 47 & 56 & trnH-UGG & LSC \\
2 & P1 & (A)10 & 10 & 637 & 646 & $p s b A$ & LSC \\
3 & P1 & (A)11 & 11 & 2104 & 2114 & matK & LSC \\
4 & P1 & (A)12 & 12 & 3942 & 3953 & trnK-UUU (intron) & LSC \\
5 & P2 & (AT)5 & 10 & 755 & 764 & $p s b A$ & LSC \\
6 & P4 & (AATT)3 & 12 & 3974 & 3985 & trnK-UUU (intron) & LSC \\
7 & P4 & (CCAT)3 & 12 & 54 & 65 & trnH-UGG & LSC \\
\hline
\end{tabular}

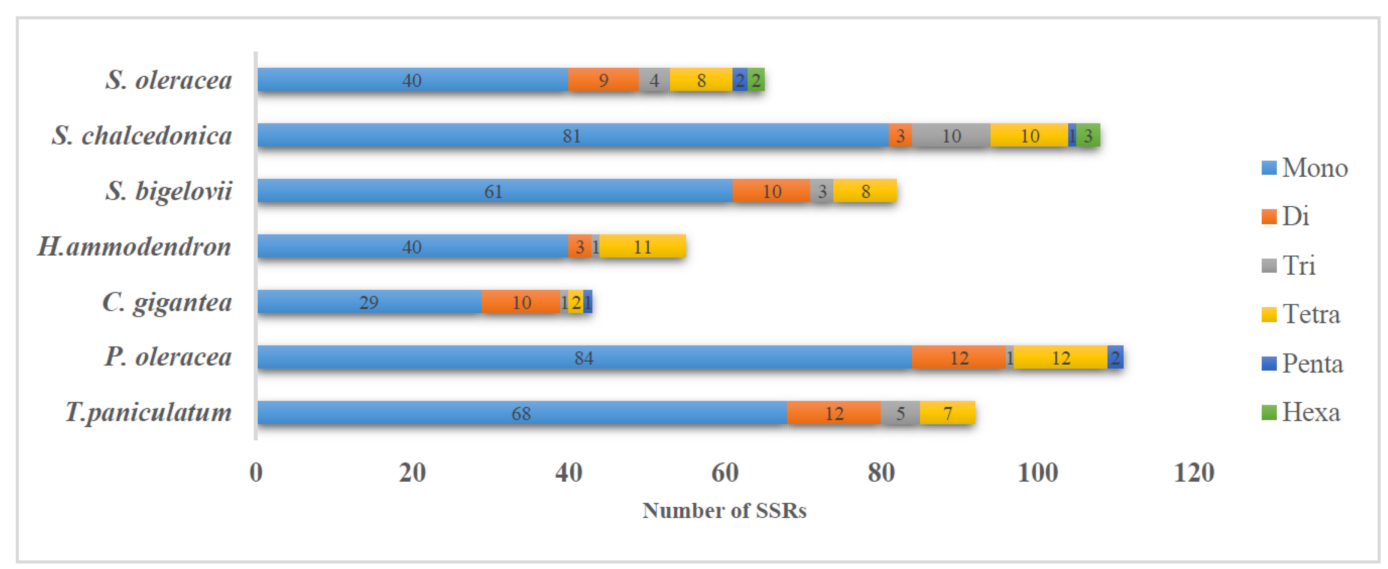

Figure 3. Distribution of SSRs present in seven chloroplast genomes of Caryophyllales.

\section{4. matK and rpl23 Diversity Analysis}

The chloroplast genes matK and rpl23 of T. paniculatum were compared with those of nine other Caryophyllaceae species. The matK sequence is often used in DNA barcoding, phylogenetic and evolutionary studies [34]. The sequences of matK genes of chloroplast DNA in T. paniculatum, P. oleracea, S. conica, S. chalcedonica, S. europaea, S. bigelovii, A. githago, H. ammodendro and S. oleracea show significant diversity by alignment analysis (Figure 4), while most of the matk (T. paniculatum, P. oleracea, S. conica, S. chalcedonica, S. europaea, S. bigelovii, A. githaggo, H. ammodendro and S. oleracea) were inserted into the introns of $t r n K-U U U$ [35]. Oddly, the matK gene is a pseudogene in S. conica, which has the shortest length [36]. The multiple alignment result revealed that the matK gene of T. paniculatum was relatively 
similar to that of P. oleracea, except for an AATT insert and eight single nucleotide polymorphisms (SNPs) (Figure 4). The matK genes from S. chalcedonica and A. githago displayed relatively high sequence similarity, due to the fact they both belong to the Sileneae in the Caryophyllaceae family [37]. The matK in S. bigelovii and S. europaea had high sequence similarity too, because they belong to the same family of Chenopodiaceae (Figure 4). These results revealed that the closer the relationship between species, the higher the sequence similarity of matK. Hence, consistent with many research results, the matK gene was one of the best choices for DNA barcoding, phylogenetic and evolutionary analysis [38-40].
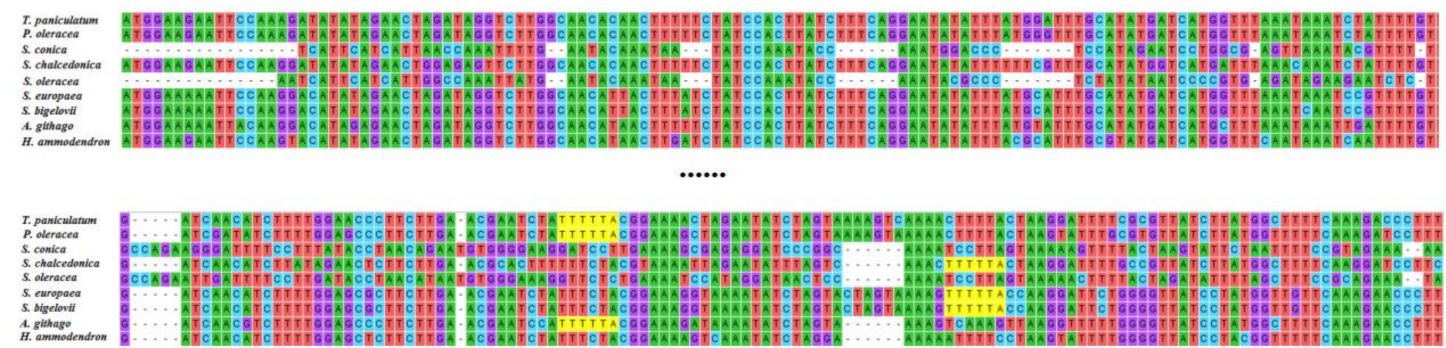

.......

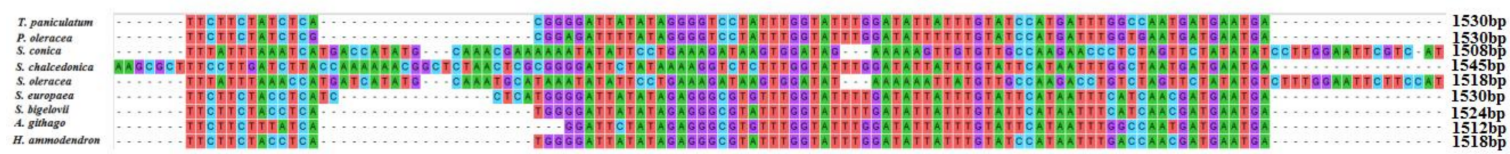

Figure 4. Sequence alignment of mat $K$ among nine species cp genome in Caryophyllales. As the mat $K$ gene are too long, only the sequences with greater variation were shown here.

Ribosomal protein L23 (rpl23) is a protein component of the 60S large ribosomal subunit and is also a negative regulator of cellular apoptosis in animals [41]. The alignment of rpl23 was carried out in T. paniculatum, P. oleracea, C. longiscapa, S. conica, H. ammodendron, S. bigelovii, S. europaea (Figure 5). The results revealed that rpl23 gene of T. paniculatum was a pseudogene as in H. ammodendron, $S$. bigelovii and S. europaea. The rpl23 gene lacked the CTTGACACCAAAGA sequence in H. ammodendron, S. bigelovii and S. europaea. However, the rpl23 of T. paniculatum had AATT inserted. Interestingly, the $r p l 23$ was not presented in A. githago, S. chalcedonica and A. hypochondriacus [37]. The rpl23 were normal genec in P. oleracea and C. longiscapa, which had some SNPs between them [42].

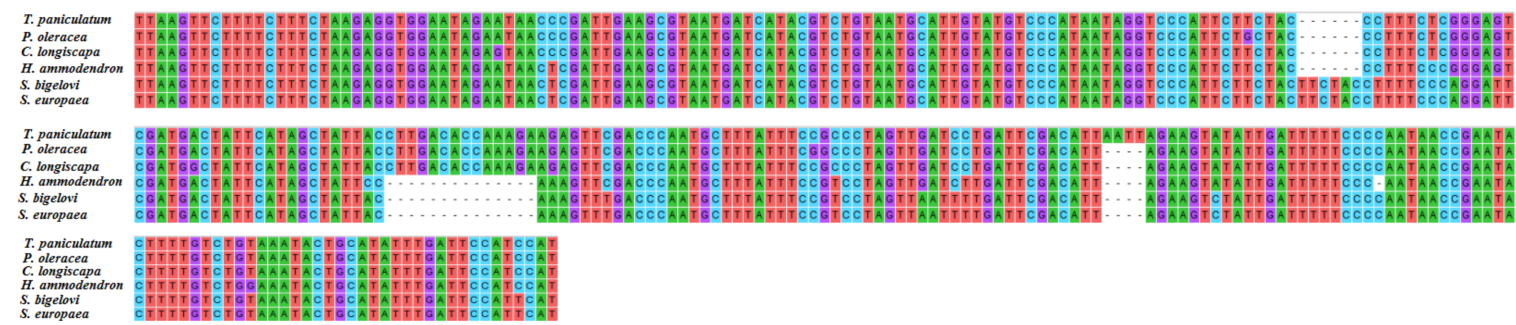

Figure 5. The gene of rpl23 sequence alignment among six Caryophyllales species.

\subsection{Comparative Analysis of the Chloroplast Genomes of the Caryophyllales}

The genome sequence of T. paniculatum was compared with eight species of Caryophyllales using the mVISTA software (Figure 6). T. paniculatum had the biggest cp genome with the biggest IR region $(25,751 \mathrm{bp})$, while $C$. gigantea had the smallest cp genome with one IR region loss [24]. The length differences among them were mainly caused by deletions in the non-coding regions. Meanwhile, the results showed that the non-coding region variation was significantly higher than that of the coding regions, and the IR region was more conserved than the LSC and SSC regions [43,44]. The matK, accD, $n d h F$, infA, trnS-GGA, trnT-UGU, trnL-UAA, trnG-UCC, ycf2, ycf1, rpl23, ccs A, ndhG and rps19 genes 
were the most divergent coding regions. The introns of $y c f 3, n d h A, r p l 16, \operatorname{clpP}$, petB, trnK-UUU, rpoC, pet $D$ were relatively highly divergent, too.

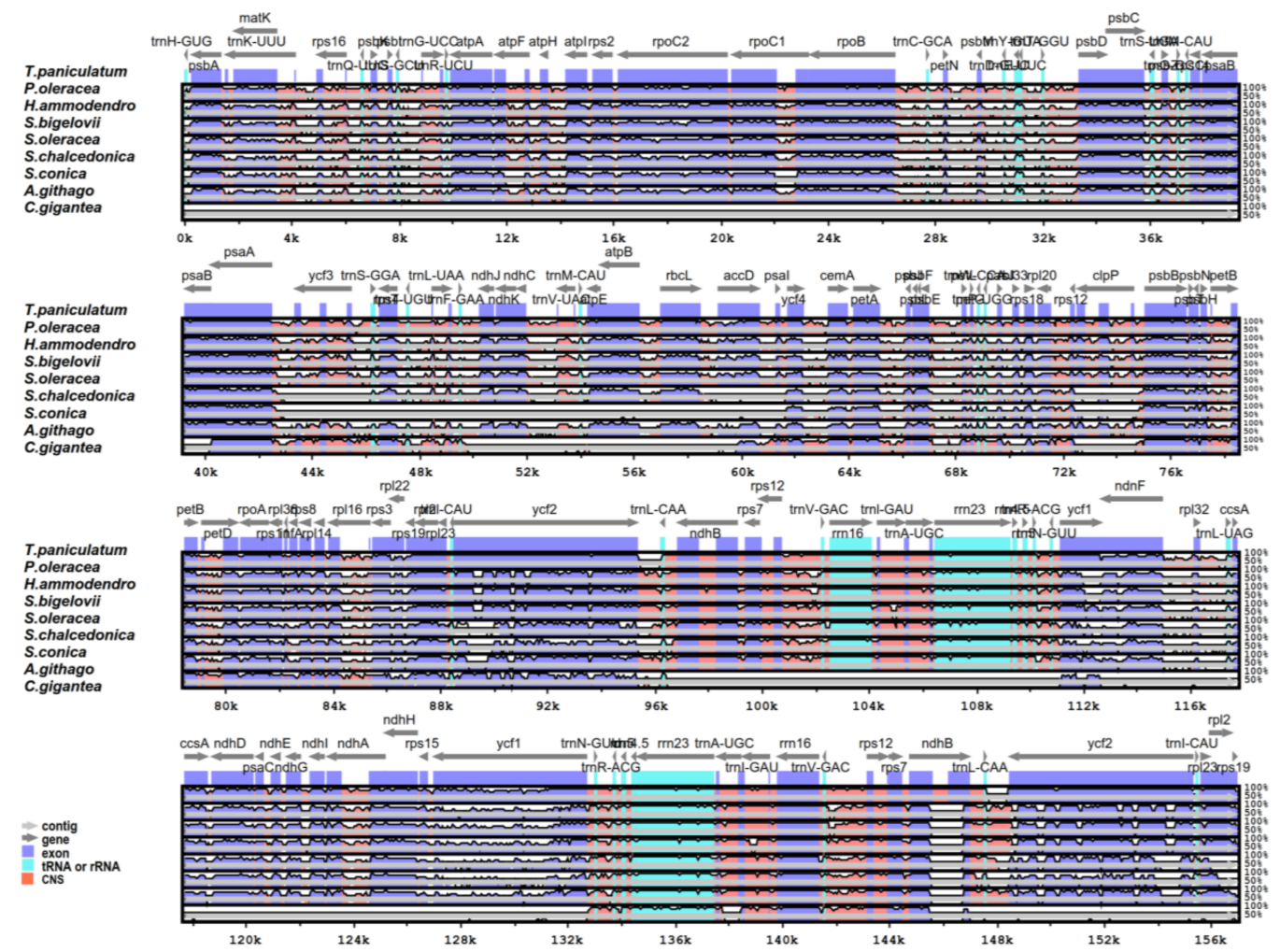

Figure 6. Complete chloroplast genome sequence comparison of eight species using mVISTA, with $T$. paniculatum as a reference. The horizontal axis corresponds to the coordinates within the chloroplast genome. The vertical scale represents the identity percentage. The grey lines and the arrows show the genes with their orientation and position. CNS: conserved noncoding sequences.

\subsection{IR Expansion and Contraction}

IR contraction and expansion of T. paniculatum was analyzed by comparing the LSC/IRb/SSC/IRa boundary regions with seven families in the Caryophyllales (Figure 7). Among them, the chloroplast genome of T. paniculatum was the longest. The $n d h F$ gene of T. paniculatum did not cross the IRb region and the SSC region, compared to P. oleracea, A. githago, A. hypochndriacus and S. oleracea, however it was the largest IR region among them (Figure 7). The rps19 gene in the T. paniculatum cp genome was shifted by $117 \mathrm{bp}$ from LSC to IRb at the LSC/IRb border, which was the smallest shift length compared to P. oleracea, A. githago, H. ammodendron, S. oleracea and S. bigelovii (Figure 7). Differently from other LSC/IRb border, the rps19 gene of $S$. chalcedonica was entirely located in the LSC region. Unlike most LSC/IRa borders, the trnH gene of S. bigelovii was located in the LSC region, and the trnH of T. paniculatum was located in the LSC region as most of them. Oddly, a significant bigger IR size but the smallest rps19 and ycf1 length in the IR region were found in T. paniculatum. This phenomenon may be for two reasons: on one hand, pseudogenes exist, and on the other hand, there is a low occurrence of contraction by the fragment deletions in the intergenic regions in T. paniculatum [32]. 
T. paniculatum

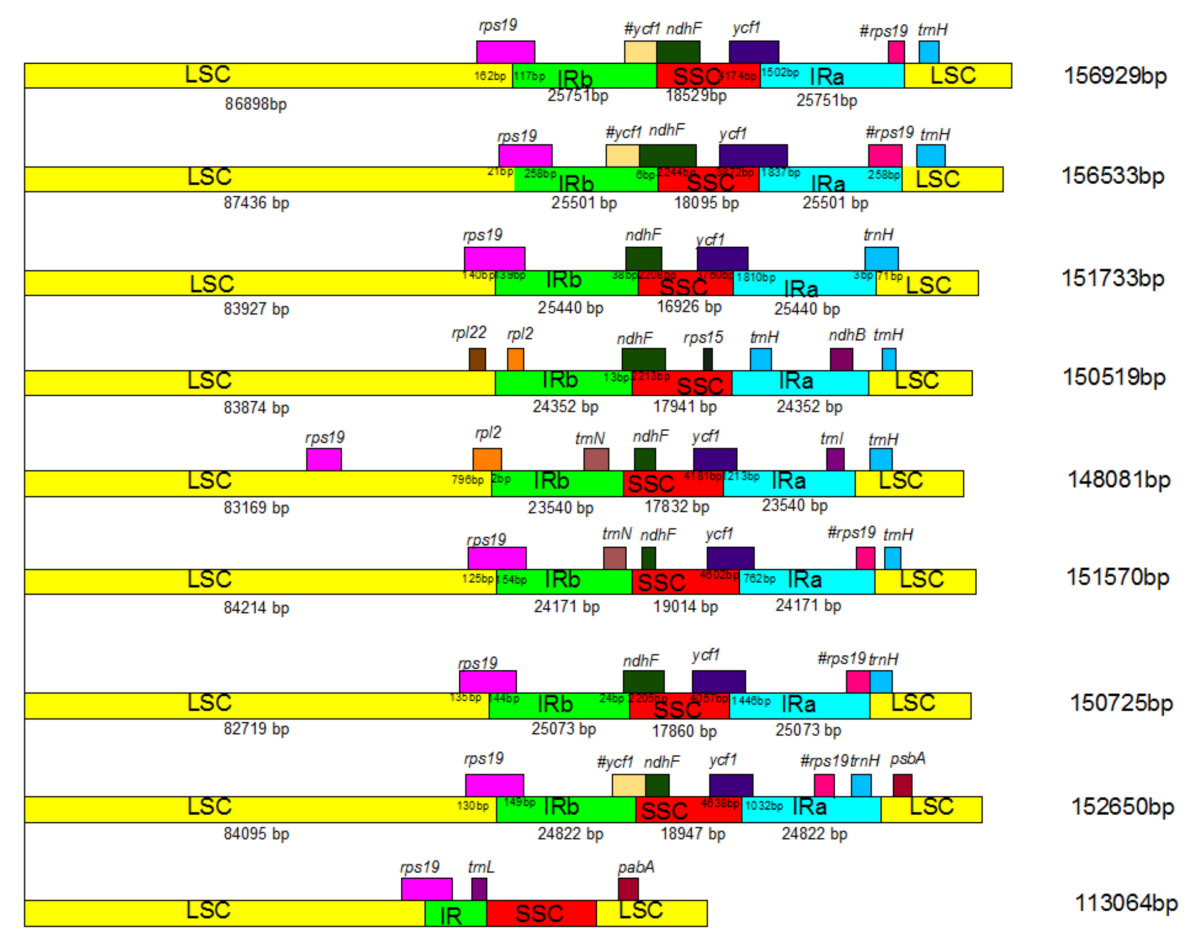

C. gigantea

Figure 7. Comparison of the borders of the LSC, SSC and IR regions in nine Caryophyllales species. \#indicates that the gene is a pseudogene.

\subsection{Phylogenetic Analysis}

The cp genome sequence is a useful resource for studying the taxonomy in the Angiosperm clade, and for analyzing evolutionary relationships within families. Here, to obtain a reasonable phylogenetic status of T. paniculatum, we performed multiple sequence alignments of cp genome protein coding genes. A total of 35 complete cp genomes of Caryophyllales and two outgroup species were subjected to phylogenetic analysis based on a 48-gene data matrix, which used the MP and ML methods. MP analysis resulted in a single tree with a length of 24,669, a consistency index (CI) of 0.6111 , and a retention index (RI) of 0.7786 (Figure 8). Bootstrap analysis showed that 28 out of the 33 nodes had bootstrap values $>95 \%$.

As we all know, the specific relationships within the Poltulaca and Talinum remain obscure due to their complex past evolutionary histories. Recently, according to molecular and morphological evidence, the Anacampserotaceae, Basellaceae, Cactaceae, Didiereaceae, Portulacaceae, and Talinaceae were classified into four single independent families [17-20]. The Portulacaeae are now comprised only a single Portulace genus [21]. However, few reports have been published on the genetic diversity of chloroplast DNA from the Anacampserotaceae, Basellaceae, Cactaceae, Didiereaceae and Portulacaceae. From Figure 8, the cp genome protein coding genes of the phylogenetic trees show that P. oleracea and T. paniculatum do not belong to the same family, although the above data shows that there are many similarities between P. oleracea and T. paniculatum, which is consistent with the recent classification studies $[20,45,46]$. Hence, whole cp genome or the key segments of evolutionary variation should be used for phylogenetic study. 


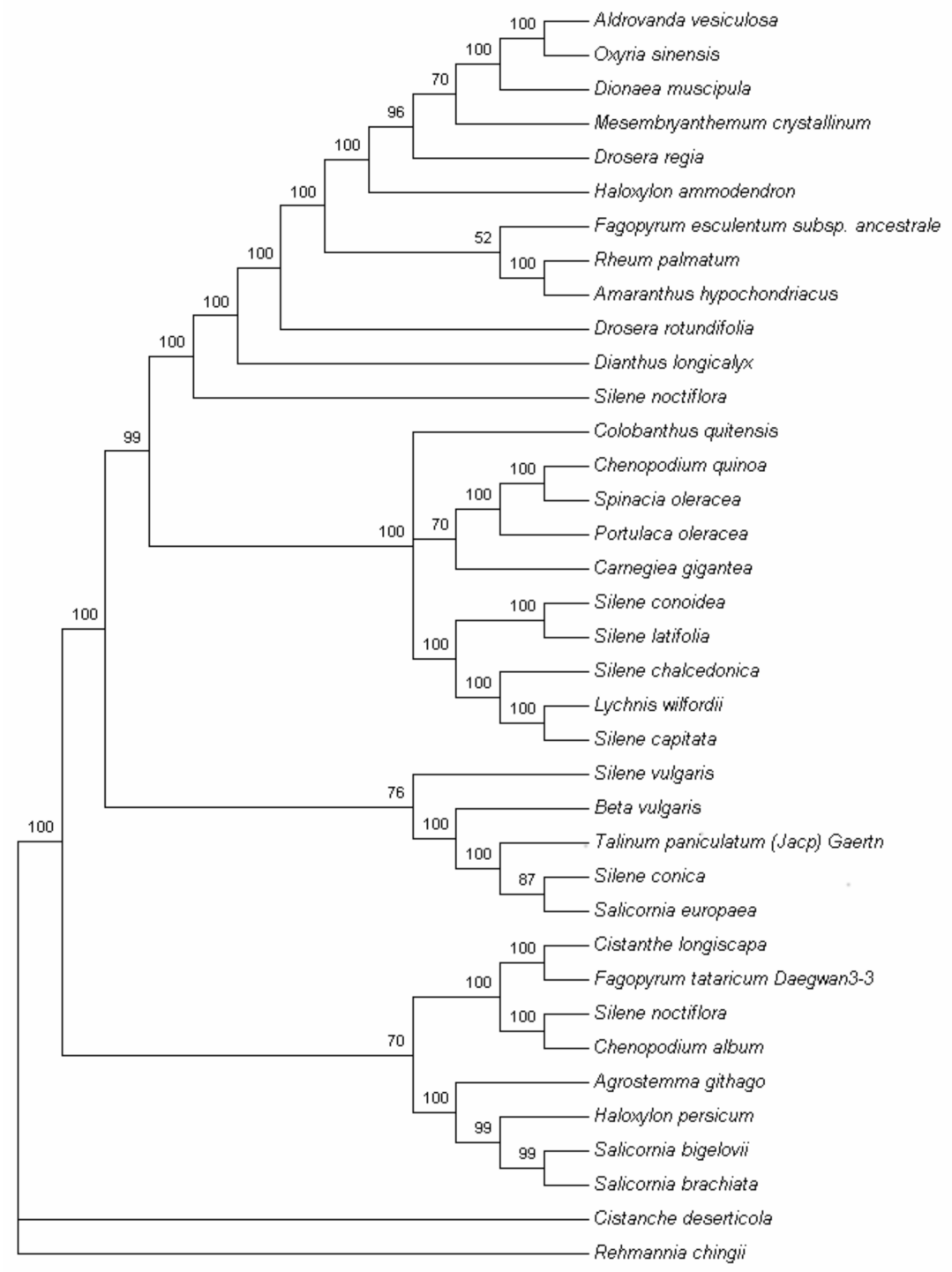

Figure 8. Phylogenetic tree of the 35 species in Caryophyllales using maximum parsimony (MP) and tree bisection-reconnection (TBR) analysis based on 48 protein-coding genes using a non-partitioning scheme. The phylogenetic tree was drawn using Cistanche deserticola and Rehmannia chingiis as outgroup.

\section{Discussion}

We report a genome sequence of T. paniculatum, which provides an important resource for studying the evolution of the Caryophyllales and the molecular breeding of T. paniculatum with high pharmaceutical efficacy. Despite the fact that the chloroplast genomes of Angiosperms are well-conserved in the genomic structure in terms of gene order and number, length variations of the whole chloroplast genome sequences and LSC, SSC and IR regions, the IR expansion and contraction occur frequently. The results reported here are congruent with the recent studies which showed that the trnH-GUG gene was situated in the LSC region in some species of Caryophyllales, while the SSC/IRA border extends into the $y c f 1$ with subsequent formation of a ycf1 pseudogene $[47,48]$. Boundary expansion and contraction between the single copy and IR boundary regions lead to sequence variation, which might be a base of plant lineages [49].

In this study, we analyzed codon usage frequency and RSCU in the T. paniculatum. As previously reported, leucine and isoleucine are the more commonly seen amino acids in the cp genomes of Angiosperms [33,50-53]. Likewise, like in earlier studies about repeats and SSRs, mononucleotide 
repeats are more abundant with A/T repeats, which is consistent with AT richness in Angiosperm chloroplast genomes [54-56]. Complement repeats were rarely found in T. paniculatum and C. gigantea [24]. Meanwhile, all of the SSRs in CDs locate in the LSC region [32]. These cp SSR markers could be a resource for molecular-marker-assisted selection breeding for T. paniculatum for production of high levels of biologically active compounds.

Here, we compared the matK and rpl23 sequences of several species of Caryophyllales. The results revealed that the pseudogene rpl23 of T. paniculatum had inserted AATT, which is different from other Caryophyllales. The gene of $m a t K$ is often used to identity the relationship between species as a barcoding marker [57]. Most reports have revealed that the closer the relationship between species, the higher the sequence similarity of matK. matK represents one of the best choices for DNA barcoding, phylogenetic and evolutionary analysis [38-40]. However, though T. paniculatum has a high matK gene similarity to P. oleracea, they belong to different families, hence, multiple marks should be used for barcoding.

\section{Conclusions}

In this study, the complete cp genome of T. paniculatum was reported and analyzed for the first time. T. paniculatum is one of the key traditional Chinese medicines used against cancer, diabetes, hepatic disorders, leishmaniasis and reproductive disorders and is also an edible vegetable. Comparing the $\mathrm{cp}$ genomes of $T$. paniculatum with other Caryophyllale species, the $\mathrm{cp}$ genome of T. paniculatum is the largest IRs, but has the smallest rps19 and ycf1 length in the IR border, most likely due to low occurrence of contraction by the fragment deletions in the intergenic regions. The pseudogene of rpl23 was inserted by AATT, and trnK-UUU and rpl16 have larger introns than other Caryophyllale species. The matK genes show rich divergence. All these results provide good opportunities for future barcoding molecular marker development. Our phylogenetic analysis showed that T. paniculatum and P. oleracea don't belong to the same family. This information will be useful for the phylogenetic study of T. paniculatum, and might also contribute to the genetics and breeding of T. paniculatum.

\section{Materials and Methods}

\subsection{DNA Sequencing and Genome Assembly}

Total DNA of T. paniculatum was obtained from approximately $100 \mathrm{~g}$ of fresh leaves using the CTAB method [58]. Quality of the DNA was evaluated by measuring $A_{260}$ using a Nanodrop2000 spectrometer (Thermo Fisher Scientific, Waltham, MA, USA). Then, the DNA was sheared to fragments of 300 500 bp. Paired-end libraries were prepared with the TruSeq ${ }^{\mathrm{TM}}$ DNA sample Prep Kit and the TruSeq PE Cluster Kit. The genome was then sequenced using the HiSeq4000 platform (Illumina Inc., San Diego, CA, USA). The assembly of the cp genome of T. paniculatum was first carried out through the error correction and production of initial contigs using the GS FLX De Novo Assembler Software (Newbler V2.6). PCR amplification and Sanger sequencing were performed to verify the four junction regions between the IRs and the LSC/SSC. The final cp genome of T. paniculatum was submitted to GenBank with the accession number MG710385.

\subsection{Gene Annotation and Codon Usage Analysis}

The cp genome was annotated by manual corrections using BLAST and DOGMA [59]. The tRNAscan-SE [60] was used to identify the tRNA genes. OGDRAW [61] was used to draw the circular genome map. MEGA5 were used for revealing the characteristics of the variations in synonymous codon usage [62]. The relative synonymous codon usage values (RSCU), codon usage and GC content were also determined by MEGA5. 


\subsection{Repeat Structure and Single Sequence Repeats (SSRs) Analysis}

Analysis of tandem repeats with more than $30 \mathrm{bp}$ and a minimum of $90 \%$ sequence (forward, palindromic, reverse and complement) and single sequence repeats (SSRs) was identified by REPuter [63] and MISA respectively, with the same parameters as described in Ni et al. [43].

\subsection{Comparative Genome Analysis of the T. paniculatum with Eight cp Genomes of Caryophyllales}

Comparison of the overall $\mathrm{cp}$ genome of $T$. paniculatum with eight $\mathrm{cp}$ genomes of Caryophyllales were performed by mVISTA [64,65], using the annotation of T. paniculatum as a reference.

\subsection{Phylogenetic Analysis}

A total of 37 complete cp genome sequences were downloaded from the NCBI Organelle Genome Resources database (http:/ / www.ncbi.nlm.nih.gov/genomes/). For the phylogenetic analysis, a set of 48 protein-coding genes that were common in the 37 analyzed genomes, was used. Maximum parsimony (MP) analysis was performed with PAUP*4.0b10 [66], using a heuristic search combined with the random addition of 1000 replicates and tree bisection-reconnection (TBR) branch swapping, in the Multrees option. Bootstrap analysis was also performed with 1000 replicates and TBR branch swapping. Rehmannia chingii and Lindenbergia philippensis were set as outgroups.

Acknowledgments: This work was supported by grants from the Natural Science Foundation of Tianjin (17JCZDJC34300) and Key Projects in the National Science and Technology Pillar Program during the Twelve Five-year Plan Period of China (2015BAD16B02).

Author Contributions: X.L. conceived and designed the experiments; Y.L. and H.Y. performed the experiments; X.L., Y.L. and B.Z. analysed the data; X.L. and Y.L. wrote the paper. All authors read and approved the final manuscript.

Conflicts of Interest: The authors declare no conflict of interest.

\section{References}

1. Cazzonelli, C.I. Carotenoids in nature: Insights from plants and beyond. Funct. Plant Biol. 2011, 38, 833-847. [CrossRef]

2. Daniell, H.; Lin, C.; Yu, M.; Chang, W. Chloroplast genomes: Diversity, evolution, and applications in genetic engineering. Genome Biol. 2016. [CrossRef] [PubMed]

3. Bobik, K.; Burch-Smith, T.M. Chloroplast signaling within, between and beyond cells. Front. Plant Sci. 2015. [CrossRef] [PubMed]

4. Bohne, A.; Schwarz, C.; Schottkowski, M.; Lidschreiber, M.; Piotrowski, M.; Zerges, W.; Nickelsen, J. Reciprocal Regulation of Protein Synthesis and Carbon Metabolism for Thylakoid Membrane Biogenesis. PLoS Biol. 2013. [CrossRef] [PubMed]

5. Song, Y.; Chen, Y.; Lv, J.; Xu, J.; Zhu, S.; Li, M.; Chen, N. Development of Chloroplast Genomic Resources for Oryza Species Discrimination. Front. Plant Sci. 2017, 8, 1854. [CrossRef] [PubMed]

6. Kang, Y.; Deng, Z.; Zang, R.; Long, W. DNA barcoding analysis and phylogenetic relationships of tree species in tropical cloud forests. Sci. Rep. UK 2017. [CrossRef] [PubMed]

7. Baczkiewicz, A.; Szczecinska, M.; Sawicki, J.; Stebel, A.; Buczkowska, K. DNA barcoding, ecology and geography of the cryptic species of Aneura pinguis and their relationships with Aneura maxima and Aneura mirabilis (Metzgeriales, Marchantiophyta). PLoS ONE 2017, 12, e0188837. [CrossRef] [PubMed]

8. Jansen, R.K.; Cai, Z.; Raubeson, L.A.; Daniell, H.; DePamphilis, C.W.; Leebens-Mack, J.; Mueller, K.F.; Guisinger-Bellian, M.; Haberle, R.C.; Hansen, A.K.; et al. Analysis of 81 genes from 64 plastid genomes resolves relationships in angiosperms and identifies genome-scale evolutionary patterns. Proc. Natl. Acad. Sci. USA 2007, 104, 19369-19374. [CrossRef] [PubMed]

9. Su, J.; Zhu, L.; Sherman, A.; Wang, X.; Lin, S.; Kamesh, A.; Norikane, J.H.; Streatfield, S.J.; Herzog, R.W.; Daniell, H. Low cost industrial production of coagulation factor IX bioencapsulated in lettuce cells for oral tolerance induction in hemophilia B. Biomaterials 2015, 70, 84-93. [CrossRef] [PubMed] 
10. Sukwan, C.; Wray, S.; Kupittayanant, S. The effects of Ginseng Java root extract on uterine contractility in nonpregnant rats. Physiol. Rep. 2014, 2, e12230. [CrossRef] [PubMed]

11. Jung, M.; Park, M.; Lee, H.C.; Kang, Y.H.; Kang, E.S.; Kim, S.K. Antidiabetic agents from medicinal plants. Curr. Med. Chem. 2006, 13, 1203-1218. [CrossRef] [PubMed]

12. Odonne, G.; Bourdy, G.; Castillo, D.; Estevez, Y.; Lancha-Tangoa, A.; Alban-Castillo, J.; Deharo, E.; Rojas, R.; Stien, D.; Sauvain, M. Ta'ta', Huayani: Perception of leishmaniasis and evaluation of medicinal plants used by the Chayahuita in Peru. Part II. J. Ethnopharmacol. 2009, 126, 149-158. [CrossRef] [PubMed]

13. Dos Reis, L.F.C.; Cerdeira, C.D.; De Paula, B.F.; Da Silva, J.J.; Coelho, L.F.L.; Silva, M.A.; Marques, V.B.B.; Chavasco, J.K.; Alves-Da-Silva, G. Chemical Characterization and Evaluation of Antibacterial, Antifungal, Antimycobacterial, and Cytotoxic Activities of Talinum paniculatum. Rev. Inst. Med. Trop. SP 2015, 57, 397-405. [CrossRef] [PubMed]

14. Thanamool, C.; Papirom, P.; Chanlun, S.; Kupittayanant, S. Talinum paniculatum (Jacq.) Gertn: A medicinal plant with potential estrogenic activity in ovariectomized rats. Int. J. Pharm. Pharm. Sci. 2013, 5, 478-485.

15. Shaw, P.C.; But, P.P. Authentication of Panax species and their adulterants by random-primed polymerase chain reaction. Planta Med. 1995, 61, 466-469. [CrossRef] [PubMed]

16. Assaha, D.V.M.; Mekawy, A.M.M.; Liu, L.; Noori, M.S.; Kokulan, K.S.; Ueda, A.; Nagaoka, T.; Saneoka, H. $\mathrm{Na}^{+}$Retention in the Root is a Key Adaptive Mechanism to Low and High Salinity in the Glycophyte, Talinum paniculatum (Jacq.) Gaertn. (Portulacaceae). J. Agron. Crop Sci. 2017, 203, 56-67. [CrossRef]

17. Nyffeler, R. The closest relatives of cacti: Insights from phylogenetic analyses of chloroplast and mitochondrial sequences with special emphasis on relationships in the tribe Anacampseroteae. Am. J. Bot. 2007, 94, 89-101. [CrossRef] [PubMed]

18. Nyffeler, R.; Eggli, U. Disintegrating Portulacaceae: A New Familial Classification of the Suborder Portulacineae (Caryophyllales) Based on Molecular and Morphological Data. Taxon 2010, 59, 227-240.

19. Nyananyo, B.L. Taxonomic studies in the genus Portulaca L. (Portulacaceae). Feddes Repert. 1987, 98, $399-402$. [CrossRef]

20. Ocampo, G.; Columbus, J.T. Molecular phylogenetics, historical biogeography, and chromosome number evolution of Portulaca (Portulacaceae). Mol. Phylogenet. Evol. 2012, 63, 97-112. [CrossRef] [PubMed]

21. Christenhusz, M.J.M.; Byng, J.W. The number of known plant species in the world and its annual increase. Phytotaxa 2016, 261, 201-217. [CrossRef]

22. Atichokudomchai, N.; Varavinit, S. Characterization and utilization of acid-modified cross-linked Tapioca starch in pharmaceutical tablets. Carbohyd. Polym. 2003, 53, 263-270. [CrossRef]

23. Liu, X.; Yang, H.; Zhao, J.; Zhou, B.; Li, T.; Xiang, B. The complete chloroplast genome sequence of the folk medicinal and vegetable plant purslane (Portulaca oleracea L.). J. Hortic. Sci. Biotechnol. 2017, 92, 1-10. [CrossRef]

24. Sanderson, M.J.; Copetti, D.; Burquez, A.; Bustamante, E.; Charboneau, J.L.M.; Eguiarte, L.E.; Kumar, S.; Lee, H.O.; Lee, J.; McMahon, M.; et al. Exceptional reduction of the plastid genome of saguaro cactus (Carnegiea gigantea): Loss of the ndh gene suite and inverted repeat. Am. J. Bot. 2015, 102, 1115-1127. [CrossRef] [PubMed]

25. Li, X.; Yang, Y.; Henry, R.J.; Rossetto, M.; Wang, Y.; Chen, S. Plant DNA barcoding: From gene to genome. Biol. Rev. Camb. Philos. Soc. 2015, 90, 157-166. [CrossRef] [PubMed]

26. Morton, B.R. Codon use and the rate of divergence of land plant chloroplast genes. Mol. Biol. Evol. 1994, 11, 231-238. [PubMed]

27. Muse, S.V.; Gaut, B.S. Comparing patterns of nucleotide substitution rates among chloroplast loci using the relative ratio test. Genetics 1997, 146, 393-399. [PubMed]

28. Muse, S.V. Examining rates and patterns of nucleotide substitution in plants. Plant Mol. Biol. 2000, 42, 25-43. [CrossRef] [PubMed]

29. Wakeley, J. Substitution-rate variation among sites and the estimation of transition bias. Mol. Biol. Evol. 1994, 11, 436-442. [PubMed]

30. Zhou, J.; Cui, Y.; Chen, X.; Li, Y.; Xu, Z.; Duan, B.; Li, Y.; Song, J.; Yao, H. Complete Chloroplast Genomes of Papaver rhoeas and Papaver orientale: Molecular Structures, Comparative Analysis, and Phylogenetic Analysis. Molecules 2018, 23, 437. [CrossRef] [PubMed] 
31. Zuo, L.; Shang, A.; Zhang, S.; Yu, X.; Ren, Y.; Yang, M.; Wang, J. The first complete chloroplast genome sequences of Ulmus species by de novo sequencing: Genome comparative and taxonomic position analysis. PLOS ONE 2017. [CrossRef] [PubMed]

32. Jian, H.; Zhang, Y.; Yan, H.; Qiu, X.; Wang, Q.; Li, S.; Zhang, S. The Complete Chloroplast Genome of a Key Ancestor of Modern Roses, Rosa chinensis var. spontanea, and a Comparison with Congeneric Species. Molecules 2018, 23, 389. [CrossRef] [PubMed]

33. Li, Z.; Saina, J.K.; Gichira, A.W.; Kyalo, C.M.; Wang, Q.; Chen, J. Comparative Genomics of the Balsaminaceae Sister Genera Hydrocera triflora and Impatiens pinfanensis. Int. J. Mol. Sci. 2018, 19, 319. [CrossRef] [PubMed]

34. Carbonell-Caballero, J.; Alonso, R.; Ibanez, V.; Terol, J.; Talon, M.; Dopazo, J. A Phylogenetic Analysis of 34 Chloroplast Genomes Elucidates the Relationships between Wild and Domestic Species within the Genus Citrus. Mol. Biol. Evol. 2015, 32, 2015-2035. [CrossRef] [PubMed]

35. Zoschke, R.; Nakamura, M.; Liere, K.; Sugiura, M.; Boerner, T.; Schmitz-Linneweber, C. An organellar maturase associates with multiple group II introns. Proc. Natl. Acad. Sci. USA 2010, 107, 3245-3250. [CrossRef] [PubMed]

36. Sloan, D.B.; Alverson, A.J.; Wu, M.; Palmer, J.D.; Taylor, D.R. Recent Acceleration of Plastid Sequence and Structural Evolution Coincides with Extreme Mitochondrial Divergence in the Angiosperm Genus Silene. Genome Biol. Evol. 2012, 4, 294-306. [CrossRef] [PubMed]

37. Sloan, D.B.; Triant, D.A.; Forrester, N.J.; Bergner, L.M.; Wu, M.; Taylor, D.R. A recurring syndrome of accelerated plastid genome evolution in the angiosperm tribe Sileneae (Caryophyllaceae). Mol. Phylogenet. Evol. 2014, 72, 82-89. [CrossRef] [PubMed]

38. Bafeel, S.O.; Arif, I.A.; Bakir, M.A.; Khan, H.A.; Al Farhan, A.H.; Al Homaidan, A.A.; Ahamed, A.; Thomas, J. Comparative evaluation of PCR success with universal primers of maturase K (matK) and ribulose-1,5-bisphosphate carboxylase oxygenase large subunit ( $r b c L)$ for barcoding of some arid plants. Plant Omics 2011, 4, 195-198.

39. Yu, J.; Xue, J.; Zhou, S. New universal matK primers for DNA barcoding angiosperms. J. Syst. Evol. 2011, 49, 176-181. [CrossRef]

40. Heckenhauer, J.; Barfuss, M.H.J.; Samuel, R. Universal Multiplexable Matk Primers for Dna Barcoding of Angiosperms. Appl. Plant Sci. 2016, 4. [CrossRef] [PubMed]

41. Qi, Y.; Li, X.; Chang, C.; Xu, F.; He, Q.; Zhao, Y.; Wu, L. Ribosomal protein L23 negatively regulates cellular apoptosis via the RPL23/Miz-1/c-Myc circuit in higher-risk myelodysplastic syndrome. Sci. Rep. 2017, 7, 2323. [CrossRef] [PubMed]

42. Stoll, A.; Harpke, D.; Schutte, C.; Stefanczyk, N.; Brandt, R.; Blattner, F.R.; Quandt, D. Development of microsatellite markers and assembly of the plastid genome in Cistanthe longiscapa (Montiaceae) based on low-coverage whole genome sequencing. PLoS ONE 2017, 12, e178402. [CrossRef] [PubMed]

43. Ni, L.; Zhao, Z.; Xu, H.; Chen, S.; Dorje, G. The complete chloroplast genome of Gentiana straminea (Gentianaceae), an endemic species to the Sino-Himalayan subregion. Gene 2016, 577, 281-288. [CrossRef] [PubMed]

44. Khakhlova, O.; Bock, R. Elimination of deleterious mutations in plastid genomes by gene conversion. Plant J. 2006, 46, 85-94. [CrossRef] [PubMed]

45. Veselova, T.D.; Dzhalilova, K.K.; Remizowa, M.V.; Timonin, A.C. Embryology of Talinum paniculatum (Jacq.) Gaertn. and T-triangulare (Jacq.) Willd. (Portulacaceae s.1., Caryophyllales). Wulfenia 2012, 19, 107-129.

46. Steyn, E.; Smith, G.F. Portulacaceae-Talinum paniculatum, a naturalized weed in South Africa. Bothalia 2001, 31, 195-197.

47. Lee, M.; Park, J.; Lee, H.; Sohn, S.; Lee, J. Complete chloroplast genomic sequence of Citrus platymamma determined by combined analysis of Sanger and NGS data. Hortic. Environ. Biotechnol. 2015, 56, 704-711. [CrossRef]

48. Su, H.; Hogenhout, S.A.; Al-Sadi, A.M.; Kuo, C. Complete Chloroplast Genome Sequence of Omani Lime (Citrus aurantiifolia) and Comparative Analysis within the Rosids. PLoS ONE 2014. [CrossRef] [PubMed]

49. Wang, W.; Messing, J. High-Throughput Sequencing of Three Lemnoideae (Duckweeds) Chloroplast Genomes from Total DNA. PLoS ONE 2011. [CrossRef] [PubMed] 
50. Yang, Y.; Zhu, J.; Feng, L.; Zhou, T.; Bei, G.; Yang, J.; Zhao, G. Plastid Genome Comparative and Phylogenetic Analyses of the Key Genera in Fagaceae: Highlighting the Effect of Codon Composition Bias in Phylogenetic Inference. Front. Plant Sci. 2018, 9. [CrossRef] [PubMed]

51. Guo, S.; Guo, L.; Zhao, W.; Xu, J.; Li, Y.; Zhang, X.; Shen, X.; Wu, M.; Hou, X. Complete Chloroplast Genome Sequence and Phylogenetic Analysis of Paeonia ostii. Molecules 2018, 23, 246. [CrossRef] [PubMed]

52. Wang, W.; Yu, H.; Wang, J.; Lei, W.; Gao, J.; Qiu, X.; Wang, J. The Complete Chloroplast Genome Sequences of the Medicinal Plant Forsythia suspensa (Oleaceae). Int. J. Mol. Sci. 2017, 18, 2288. [CrossRef] [PubMed]

53. Shen, X.; Wu, M.; Liao, B.; Liu, Z.; Bai, R.; Xiao, S.; Li, X.; Zhang, B.; Xu, J.; Chen, S. Complete Chloroplast Genome Sequence and Phylogenetic Analysis of the Medicinal Plant Artemisia annua. Molecules 2017, 22, 1330. [CrossRef] [PubMed]

54. Saina, J.K.; Gichira, A.W.; Li, Z.; Hu, G.; Wang, Q.; Liao, K. The complete chloroplast genome sequence of Dodonaea viscosa: Comparative and phylogenetic analyses. Genetica 2018, 146, 101-113. [CrossRef] [PubMed]

55. Zhou, J.; Chen, X.; Cui, Y.; Sun, W.; Li, Y.; Wang, Y.; Song, J.; Yao, H. Molecular Structure and Phylogenetic Analyses of Complete Chloroplast Genomes of Two Aristolochia Medicinal Species. Int. J. Mol. Sci. 2017, 18, 1839. [CrossRef] [PubMed]

56. Zhou, T.; Chen, C.; Wei, Y.; Chang, Y.; Bai, G.; Li, Z.; Kanwal, N.; Zhao, G. Comparative Transcriptome and Chloroplast Genome Analyses of Two Related Dipteronia Species. Front. Plant. Sci. 2016, 7. [CrossRef] [PubMed]

57. Abugalieva, S.; Volkova, L.; Genievskaya, Y.; Ivaschenko, A.; Kotukhov, Y.; Sakauova, G.; Turuspekov, Y. Taxonomic assessment of Allium species from Kazakhstan based on ITS and matK markers. BMC Plant Biol. 2017, 172. [CrossRef] [PubMed]

58. Allen, G.C.; Flores-Vergara, M.A.; Krasynanski, S.; Kumar, S.; Thompson, W.F. A modified protocol for rapid DNA isolation from plant tissues using cetyltrimethylammonium bromide. Nat. Protoc. 2006, 1, 2320-2325. [CrossRef] [PubMed]

59. Wyman, S.K.; Jansen, R.K.; Boore, J.L. Automatic annotation of organellar genomes with DOGMA. Bioinformatics 2004, 20, 3252-3255. [CrossRef] [PubMed]

60. Schattner, P.; Brooks, A.N.; Lowe, T.M. The tRNAscan-SE, snoscan and snoGPS web servers for the detection of tRNAs and snoRNAs. Nucl. Acids Res. 2005, 33, W686-W689. [CrossRef] [PubMed]

61. Lohse, M.; Drechsel, O.; Bock, R. OrganellarGenomeDRAW (OGDRAW): A tool for the easy generation of high-quality custom graphical maps of plastid and mitochondrial genomes. Curr. Genet. 2007, 52, 267-274. [CrossRef] [PubMed]

62. Tamura, K.; Peterson, D.; Peterson, N.; Stecher, G.; Nei, M.; Kumar, S. MEGA5: Molecular evolutionary genetics analysis using maximum likelihood, evolutionary distance, and maximum parsimony methods. Mol. Biol. Evol. 2011, 28, 2731-2739. [CrossRef] [PubMed]

63. Kurtz, S.; Choudhuri, J.V.; Ohlebusch, E.; Schleiermacher, C.; Stoye, J.; Giegerich, R. REPuter: The manifold applications of repeat analysis on a genomic scale. Nucl. Acids Res. 2001, 29, 4633-4642. [CrossRef] [PubMed]

64. Kurtz, S.; Phillippy, A.; Delcher, A.L.; Smoot, M.; Shumway, M.; Antonescu, C.; Salzberg, S.L. Versatile and open software for comparing large genomes. Genome Biol. 2004, 5, R12. [CrossRef] [PubMed]

65. Frazer, K.A.; Pachter, L.; Poliakov, A.; Rubin, E.M.; Dubchak, I. VISTA: Computational tools for comparative genomics. Nucl. Acids Res. 2004, 32, W273-W279. [CrossRef] [PubMed]

66. Swofford, D.L. PAUP*. Phylogenetic Analysis Using Parsimony (*and Other Methods); Version 4.0b10; Sinauer Associates: Sunderland, MA, USA, 2003.

Sample Availability: Samples of the T. paniculatum are available from the authors. 